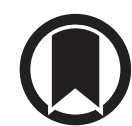

CrossMark

\section{Functional characteristics of patients with SARS-CoV-2 pneumonia at 30 days post-infection}

\author{
To the Editor:
}

We read with great interest the series of cases reported by Mo et al. [1], describing pulmonary function after severe acute respiratory syndrome coronavirus 2 (SARS-CoV-2) infection in hospitalised patients. The authors describe a significant correlation between diffusing capacity of the lung for carbon monoxide $\left(D_{\text {LCO }}\right)$ and clinically defined pneumonia severity.

Lung involvement of varying extent has been found on computed tomography (CT) in at least $80 \%$ of patients with SARS-CoV-2 infection [2,3]. Extensive injury to alveolar epithelial cells and endothelial cells, with secondary fibroproliferation is a signature of pulmonary SARS-CoV-2 infection [4] and indicates a potential for chronic vascular and alveolar remodelling leading to lung fibrosis and/or pulmonary hypertension.

We conducted a retrospective study in patients with SARS-CoV-2 pneumonia to assess the pulmonary functional status 1 month after symptom onset and correlate lung function alteration with the severity of pneumonia.

Patients under the age of 85 years with confirmed SARS-CoV-2 infection (positive RT-PCR on nasopharyngeal swab) and respiratory symptoms, discharged from Bichat Hospital, Paris, France between 4 March, 2020 and 1 April, 2020, were evaluated with pulmonary function tests (PFTs) 30 days after symptom onset [5], as part of routine care. All tests included spirometry, functional residual capacity (FRC), total lung capacity (TLC) and $D_{\mathrm{LCO}}$ (single breath real-time $\mathrm{CO} / \mathrm{NH}_{4}$ ) measurements. FRC was measured by helium dilution (Masterscreen PFT, The Surgical Company, Flaxlanden, France) in non-smokers and by bodyplethysmography (Vyntus Body, The Surgical Company) in smokers. Predicted values from the Global Lung Function Initiative (GLI) were used for forced vital capacity (FVC) and $D_{\text {LCO }}$ [6]. A senior radiologist (M-P. Debray) reviewed all chest CT and evaluated the extent of pneumonia as absent, mild $(<10 \%$ of parenchyma involved), moderate $(10-24 \%)$, wide $(25-49 \%)$, or severe $(\geqslant 50 \%)$, according to European guidelines [7]. For the analysis, we classified patients into three groups according to the extent of pneumonia: none or mild, moderate, and wide-to-severe. For patients with several CT scans during the disease course, we retained the highest extent of parenchymal involvement. We assessed correlations between PFT values and body mass index (BMI), and age. Finally, we classified patients in three groups of clinical severity based on oxygen requirement during disease course: none, $0.5-6 \mathrm{~L} \cdot \mathrm{min}^{-1}$, and $>6 \mathrm{~L} \cdot \mathrm{min}^{-1} /$ high flow/invasive ventilation. Comparisons between groups used Mann-Whitney and Kruskal-Wallis tests for continuous variables, and chi-squared or Fischer's exact tests for categorical variables (Prims 8, Graphpad, San Diego, CA, USA). Non-opposition was obtained for all patients, according to French law.

56 patients were recruited, five declined to participate and one had recurrence of symptoms, leading to the assessment of 50 patients. One patient could not perform $D_{\mathrm{LCO}}$ and high-resolution CT (HRCT) was not performed in five patients. Patients' characteristics and PFT results are described in table 1. There was no difference between groups regarding BMI, age or comorbidities. Prevalence of hypertension and diabetes mellitus were $48 \%$ and $16 \%$, respectively. At the time of functional assessment, median peripheral oxygen saturation (room air) was $96 \%$. Among patients without HRCT, three had normal PFT, one had restrictive

@ERSpublications

More than half of patients with COVID-19 pneumonia exhibit abnormal lung function 30 days after symptom onset, without clear relationship with pneumonia extent on chest CT. This pleads for systematic and long-term follow-up of patients with COVID-19. https://bit.ly/2TFMPqE

Cite this article as: Frija-Masson J, Debray M-P, Gilbert M, et al. Functional characteristics of patients with SARS-CoV-2 pneumonia at 30 days post-infection. Eur Respir J 2020; 56: 2001754 [https://doi.org/ 10.1183/13993003.01754-2020]. 
TABLE 1 Patient characteristics

\begin{tabular}{|c|c|c|c|c|c|}
\hline & All & No $C T$ & None/mild & Moderate & Severe \\
\hline Subjects $\mathrm{n}$ & 50 & 5 & 12 & 17 & 16 \\
\hline Age years & $54(46-62)$ & $30(30-46)$ & $55(46-63)$ & $53(47-56)$ & $58(49-67)$ \\
\hline BMI $\mathrm{kg} \cdot \mathrm{m}^{-2}$ & $27.0(24.6-32.5)$ & $24.0(21.0-25.0)$ & $28.5(25.0-34.0)$ & $28.0(24.5-31.0)$ & $27.0(25.8-31.5)$ \\
\hline \multicolumn{6}{|l|}{ Respiratory comorbidities } \\
\hline Emphysema & $2(4)$ & $0(0)$ & $1(8)$ & $1(6)$ & $0(0)$ \\
\hline \multicolumn{6}{|l|}{ Smoking history } \\
\hline Active & $5(10)$ & $0(0)$ & $1(8)$ & $3(18)$ & $1(6)$ \\
\hline Former & $9(18)$ & $0(0)$ & $2(17)$ & $3(18)$ & $4(25)$ \\
\hline \multicolumn{6}{|l|}{ Care modality } \\
\hline Out-patient & $9(18)$ & $4(80)$ & $4(33)$ & $1(6)$ & $0(0)$ \\
\hline Infectious diseases ward & $33(66)$ & $1(20)$ & $8(66)$ & $15(88)$ & $9(56)$ \\
\hline Oxygen $\geqslant 12 \mathrm{~L} \cdot \mathrm{min}^{-1}$ & $1(2)$ & $0(0)$ & $0(0)$ & $0(0)$ & $1(6)$ \\
\hline High flow oxygen & $4(8)$ & $0(0)$ & $0(0)$ & $0(0)$ & $4(25)$ \\
\hline Invasive ventilation & $1(2)$ & $0(0)$ & $0(0)$ & $0(0)$ & $1(6)$ \\
\hline FVC $\%$ pred & 93 (85-99) & 101 (93-102) & 93.5 (88-97) & $87(85-101)$ & $90(81-96)$ \\
\hline TLC \% pred & $91.5(81-103)$ & $104(102-120)$ & 97.5 (91-103) & $91(81-101)$ & 82.5 (77-92) \\
\hline$D_{\text {Lco }} \%$ pred & $80(70-92)$ & $90(81-91)$ & 87 (73-92) & 81 (72-93) & $71(57-78)$ \\
\hline$K_{\text {co }} \%$ pred & 94 (78-108) & $96(76-99)$ & 99 (77-108) & 101 (89-111) & 90 (84-95) \\
\hline FEV $_{1} \%$ pred & $93(83-100)$ & $104(93-111)$ & $92(85-96)$ & 91 (82-97) & $92(85-104)$ \\
\hline $\mathrm{FEV}_{1} / \mathrm{FVC}$ & $0.81(0.75-0.87)$ & $0.85(0.84-0.87)$ & $0.78(0.74-0.84)$ & $0.79(0.77-0.87)$ & $0.84(0.75-0.88)$ \\
\hline \multicolumn{6}{|l|}{ PFT interpretation } \\
\hline Normal & $23(46)$ & $3(60)$ & $8(66)^{*}$ & $9(53)^{*}$ & $3(19) *$ \\
\hline Restrictive pattern & $6(12)$ & $1(20)$ & $0(0)$ & $3(18)$ & $2(13)$ \\
\hline Restriction with altered diffusion capacity & $8(16)$ & $0(0)$ & $0(0)$ & $2(12)$ & $6(38)$ \\
\hline
\end{tabular}

Data are presented as median (interquartile range) or $\mathrm{n}(\%)$, unless otherwise stated. Extent of pneumonia on computed tomography (CT) was defined as absent, mild $(<10 \%)$, moderate $(10-24 \%)$ or wide-to-severe $(\geqslant 25 \%)$ [7]. BMI: body mass index; ICU: intensive care unit; FVC: forced vital capacity; TLC: total lung capacity; $D_{\mathrm{LCO}}$ : diffusing capacity of the lung for carbon monoxide; $K_{\mathrm{CO}}$ : transfer coefficient of the lung for carbon monoxide; $\mathrm{FEV}_{1}$ : forced expiratory volume in $1 \mathrm{~s}$; PFT: pulmonary function test. *: $p<0.05$.

pattern and one had isolated low $D_{\mathrm{LCO}}$. More than half of patients $(27 / 50)$ had impaired lung function, with a mix of restrictive and low diffusion patterns. We found no difference in FVC, TLC or $D_{\text {LCO }}(\%$ predicted values) between groups according to CT extent, but a significant difference in the proportion of abnormal values (i.e. restriction and/or altered $\left.D_{\mathrm{LCO}}\right)(\mathrm{p}=0.0277)$. Lower $D_{\mathrm{LCO}}$ was significantly associated with older age ( $>50$ years) $(\mathrm{p}=0.0351)$, but TLC and FVC were not. Finally, FVC, TLC and $D_{\text {LCO }}$ were not significantly different between groups of clinical severity (i.e. oxygen requirement).

Overall, our study shows that 1 month after SARS-CoV-2 infection, a majority of patients have mild alterations of lung function. Unlike Mo et al. [1], we classified patients according to chest CT, which has been shown to have high sensitivity, even in patients with mild symptoms [2,7], in addition to clinical severity. By contrast to that reported by Mo et al. [1], our population is comparable to published series, with overweight patients, a predominance of men, and a high prevalence of hypertension. Other strengths are the systematic PFT assessment in patients with initial respiratory symptoms, the use of GLI reference equations with real-time single breath $D_{\mathrm{LCO}}$ measurement, and the CT assessment of the extent of lung involvement during the acute phase.

Noteably, we included neither patients with acute respiratory distress syndrome, since most were still hospitalised at the time of our study, nor patients over 85 years, because of the lack of valuable predicted values. This could lead to underestimation of the percentage of patients with functional impairment. Another limit is the lack of functional data prior to SARS-CoV-2 infection, but most patients were devoid of known respiratory disease history. We did not systematically perform chest CT at 30 days, due to 
limited access in the context of the epidemic and radiation dose limitation. Of note, in a study conducted by WANG et al. [3], 94\% of discharged patients had residual disease on final CT scans, although the median illness duration from symptom onset to hospital discharge was 25 days; it is thus possible that HRCT in our patients were still abnormal despite normal PFT results. Last, due to the limited number of patients, the absence of approved specific treatment and the retrospective design, we could not assess the effect of treatment on the functional recovery.

Abnormal lung function tests in more than $50 \%$ of the patients raise concern regarding potential progression towards lung fibrosis, especially taking into account the lung alveolar epithelial cell tropism [8]. In addition, isolated decreased $D_{\text {LCO }}$ in 13/50 (26\%) patients may also lead to the hypothesis of a vascular damage induced by SARS-CoV-2 [9]. The pathogenicity of SARS-CoV-2 pneumonia to date is still debated, with some post mortem biopsies showing acute fibrinous and organising pneumonia rather than diffuse alveolar damage [10], rending functional evolution of patients difficult to predict. The poor correlation between extent of pneumonia on CT and PFT findings renders difficult the a priori evaluation of prognosis, with patients presenting abnormal results despite mild disease on CT. Altogether these results plead for systematic functional assessment of SARS-CoV-2 patients with initial respiratory symptoms and long-term follow-up with HRCT and PFT. Larger studies, involving older patients and comparing the evolution of patients under different treatments, are also needed.

Justine Frija-Masson $\circledast^{1,2}$, Marie-Pierre Debray ${ }^{3,4}$, Marie Gilbert ${ }^{5}$, François-Xavier Lescure ${ }^{5,6}$, Florence Travert ${ }^{7}$, Raphaël Borie $\overbrace{}^{4,8}$, Antoine Khalil ${ }^{3,4}$, Bruno Crestani ${ }^{4,8}$, Marie-Pia d'Ortho ${ }^{1,2}$ and Catherine Bancal ${ }^{1}$

${ }^{1}$ Physiologie-Explorations Fonctionnelles, FHU APOLLO, Assistance Publique Hôpitaux de Paris, Hôpital Bichat-Claude Bernard, Paris, France. ${ }^{2}$ Université de Paris, Inserm U 1141, Paris, France. ${ }^{3}$ Assistance Publique Hôpitaux de Paris, Hôpital Bichat Claude Bernard, Service de radiologie, Paris, France. ${ }^{4}$ Université de Paris, Inserm U 1152, Paris, France.

${ }^{5}$ Assistance Publique Hôpitaux de Paris, Hôpital Bichat Claude Bernard, Service de maladies infectieuses et tropicales, Paris, France. ${ }^{6}$ Université de Paris, Inserm U 1137, Paris, France. ${ }^{7}$ Assistance Publique Hôpitaux de Paris, Hôpital Bichat Claude Bernard, Service d'endocrinologie, Paris, France. ${ }^{8}$ Assistance Publique Hôpitaux de Paris, Hôpital Bichat Claude Bernard, Service de pneumologie, Paris, France.

Correspondence: Justine Frija-Masson, Service de Physiologie, Hôpital Bichat Claude Bernard, 46 rue Henri Huchard, 75018 Paris, France. E-mail: justine.frija@aphp.fr

Received: 12 May 2020 | Accepted after revision: 22 May 2020

Acknowledgements: The authors are thankful to the patients and to the PFT technicians.

Conflict of interest: J. Frija-Masson has nothing to disclose. M-P. Debray has nothing to disclose. M. Gilbert has nothing to disclose. F-X. Lescure reports personal fees for development of presentations from Gilead and MSD, and personal fees for travel/accommodation and meeting expenses from Astellas, Eumedica and MSD, outside the submitted work. F. Travert has nothing to disclose. R. Borie reports grants and personal fees from Roche, Boehringer Ingelheim and Savara, outside the submitted work. A. Khalil has nothing to disclose. B. Crestani has nothing to disclose. M-P. d'Ortho has nothing to disclose. C. Bancal has nothing to disclose.

\section{References}

1 Mo X, Jian W, Su Z, et al. Abnormal pulmonary function in COVID-19 patients at time of hospital discharge. Eur Respir J 2020; 55: 2001217.

2 Dai H, Zhang X, Xia J, et al. High-resolution chest CT features and clinical characteristics of patients infected with COVID-19 in Jiangsu, China. Int J Infect Dis 2020; 95: 106-112.

3 Wang Y, Dong C, Hu Y, et al. Temporal changes of CT findings in 90 patients with COVID-19 pneumonia: a longitudinal study. Radiology 2020; 296: E555-E64.

4 Venkataraman T, Frieman MB. The role of epidermal growth factor receptor (EGFR) signaling in SARS coronavirus-induced pulmonary fibrosis. Antiviral Res 2017; 143: 142-150.

5 European Respiratory Society. Recommendation from ERS Group 9.1 (Respiratory Function Technologists/ Scientists). Lung Function Testing during COVID-19 Pandemic and Beyond. https://ers.app.box.com/s/ zs1uu88wy51monr0ewd990itoz4tsn2h Date last accessed 6 May, 2020.

6 Stanojevic S, Graham BL, Cooper BG, et al. Official ERS technical standards: Global Lung Function Initiative reference values for the carbon monoxide transfer factor for Caucasians. Eur Respir J 2017; 50: 1700010.

7 Revel MP, Parkar AP, Prosch H, et al. COVID-19 patients and the radiology department - advice from the European Society of Radiology (ESR) and the European Society of Thoracic Imaging (ESTI). Eur Radiol 2020; in press [https://doi.org/10.1007/s00330-020-06865-y].

8 Ziegler CGK, Allon SJ, Nyquist SK, et al. SARS-CoV-2 receptor ACE2 is an interferon-stimulated gene in human airway epithelial cells and is detected in specific cell subsets across tissues. Cell 2020; 181: 1016-1035.

9 Guzik TJ, Mohiddin SA, Dimarco A, et al. COVID-19 and the cardiovascular system: implications for risk assessment, diagnosis, and treatment options. Cardiovasc Res 2020; 116: 1666-1687.

10 Copin MC, Parmentier E, Duburcq T, et al. Time to consider histologic pattern of lung injury to treat critically ill patients with COVID-19 infection. Intensive Care Med 2020; 46: 1124-1126. 